\title{
Post-growth annealing induced change of conductivity in As-doped ZnO grown by radio frequency magnetron sputtering
}

\author{
C. K. To, B. Yang, S. C. Su, C. C. Ling, ${ }^{\text {a) }}$ C. D. Beling, and S. Fung \\ Department of Physics, The University of Hong Kong, Pokfulam Road, Hong Kong, People's Republic of China
}

(Received 6 July 2011; accepted 31 October 2011; published online 9 December 2011)

\begin{abstract}
Arsenic-doped $\mathrm{ZnO}$ films were fabricated by radio frequency magnetron sputtering method at a relatively low substrate temperature of $200^{\circ} \mathrm{C}$. Post-growth annealing in air was carried out up to a temperature of $1000^{\circ} \mathrm{C}$. The samples were characterized by Hall measurement, positron annihilation spectroscopy (PAS), secondary ion mass spectroscopy (SIMS), and cathodoluminescence (CL). The as-grown sample was of $n$-type and it converted to $p$-type material after the $400{ }^{\circ} \mathrm{C}$ annealing. The resulting hole concentration was found to increase with annealing temperature and reached a maximum of $6 \times 10^{17} \mathrm{~cm}^{-3}$ at the annealing temperature of $600^{\circ} \mathrm{C}$. The origin of the $p$-type conductivity was consistent with the $\mathrm{As}_{\mathrm{Zn}}\left(\mathrm{V}_{\mathrm{Zn}}\right)_{2}$ shallow acceptor model. Further increasing the annealing temperature would decrease the hole concentration of the samples finally converted the sample back to $n$-type. With evidence, it was suggested that the removal of the $p$-type conductivity was due to the dissociation of the $\mathrm{As}_{\mathrm{Zn}}\left(\mathrm{V}_{\mathrm{Zn}}\right)_{2}$ acceptor and the creation of the deep level defect giving rise to the green luminescence. (C) 2011 American Institute of Physics.
\end{abstract}

[doi:10.1063/1.3665713]

\section{INTRODUCTION}

$\mathrm{ZnO}$ is a wide bandgap material having physical properties suitable for fabricating UV-optoelectronic and spintronic devices. $^{1,2}$ It is generally known that defects play an important role in determining the optical and electrical properties of semiconductor materials. One of the important issues to address for successfully developing ZnO-based device technology is to overcome the asymmetric $p$-type doping difficulty of $\mathrm{ZnO}^{3,4}$ Many efforts have been devoted in this aspect, but reliable and reproducible p-type doping in $\mathrm{ZnO}$ has not yet been achieved. One of the important obstacles for achieving $p$-type doping in $\mathrm{ZnO}$ is the formation of compensating defects. ${ }^{3,4}$ For the dopant arsenic, $\mathrm{As}_{\mathrm{O}}$ is a deep acceptor and $\mathrm{As}_{\mathrm{Zn}}$ is a donor, but the associated defect complex $A s_{Z n}-2 V_{Z n}$ is a shallow acceptor. All these aspects imply that a thorough understanding of defects, their evolution, and their inter-reaction is crucially important for achieving reliable $p$-type doping in $\mathrm{ZnO}$. However, the understanding of defects in $\mathrm{ZnO}$ is far from complete.

Positron annihilation spectroscopy (PAS) is a probe selectively sensitive to neutral or negatively charged vacancy type defects, and it has been widely applied in studying vacancy in semiconductor materials. ${ }^{5,6}$ Positrons injected into the solid would be rapidly thermalized and then undergo diffusion. The principle of PAS is that neutral or negatively charged vacancy would present as an attractive potential well to positron, and thus would trap the diffusing positron from its delocalized state. The electronic environment (namely, the electronic momentum distribution or the electronic density of the vacancy delocalized state) at which the positron annihilates is revealed by measuring the corresponding Doppler broadening of the annihilation radiation (DBAR) and the positron lifetime,

\footnotetext{
a) Author to whom correspondence should be addressed. Electronic mail: ccling@hku.hk.
}

respectively. PAS has been employed to study defects in various $\mathrm{ZnO}$-related structures, such as $\mathrm{ZnO}$ bulk, ${ }^{7-11}$ thin film, ${ }^{12-14}$ nanorod structure, ${ }^{15,16}$ metal-ZnO interface, ${ }^{17,18}$ ion-implanted $\mathrm{ZnO},{ }^{19,20}$ as well as defect related phenomenon, such as intrinsic defect associated ferromagnetism. ${ }^{21}$

We have recently carried out systematic study on fabricating arsenic doped p-type $\mathrm{ZnO}$ (Ref. 14) and $\mathrm{ZnMgO}$ (Ref. 22) films by radio frequency (RF) magnetron sputtering. It was found that the carrier conduction type and concentration were highly dependent on the substrate temperature during the growth process. $n$-type $\mathrm{ZnO}$ film was obtained at a low substrate temperature such as $200^{\circ} \mathrm{C}$. Reproducible $p$-type $\mathrm{ZnO}$ film having a hole concentration of $\sim 10^{18} \mathrm{~cm}^{-3}$ and a mobility of $\sim 6 \mathrm{~cm}^{2} \mathrm{~V}^{-1} \mathrm{~s}^{-1}$ was only achieved with a critical substrate temperature (at $450{ }^{\circ} \mathrm{C}$ ). The $n$-type to $p$-type conductivity conversion was attributed to the formation of the $\mathrm{As}_{\mathrm{Zn}}\left(\mathrm{V}_{\mathrm{Zn}}\right)_{2}$ shallow acceptor complex and to the reduction of the hydrogen compensating donor.

In the present study, post-growth annealing study was performed on As-doped $\mathrm{ZnO}$ film grown at a low substrate temperature of $200^{\circ} \mathrm{C}$. $n$-type to $p$-type conversion was observed after the $400{ }^{\circ} \mathrm{C}$ annealing. The hole concentration increased after the $600{ }^{\circ} \mathrm{C}$ annealing. However, the hole concentration decreased and then returned to $n$-type if the annealing temperature further increased. PAS and cathodoluminescence (CL) were used to characterize the defects inside the materials in order to understand the mechanisms associated with the conductivity changes.

\section{EXPERIMENTAL}

Details of the RF magnetron sputtering growth are given in Refs. 14 and 22. With RF magnetron sputtering, the As-doped $\mathrm{ZnO}$ films used in the present study were grown on the $\mathrm{SiO}_{2}$ substrates at a substrate temperature of $200^{\circ} \mathrm{C}$. 
The ceramic target contained $\mathrm{Zn}_{3} \mathrm{As}_{2}(1 \mathrm{~mol} \%)$ and $\mathrm{ZnO}$ $(99 \mathrm{~mol} \%)$. The base pressure of the growth chamber was $10^{-3} \mathrm{~Pa}$. The RF power was kept at $120 \mathrm{~W}$. Secondary ion mass spectroscopy (SIMS) depth profiling measurements (Physical Electronics model 7200) showed that the fabricated film had a thickness of $\sim 280 \mathrm{~nm}$ and the As atoms were uniformly distributed with a density of $10^{19}-10^{20} \mathrm{~cm}^{-3}$. The $\mathrm{Zn}$ to $\mathrm{O}$ atomic ratio was 1.21 . The $\mathrm{X}$-ray diffraction XRD spectrum had a single peak at $2 \theta=34.47^{\circ}$ (i.e., the $\mathrm{ZnO}(002)$ peak) and a fwhm $=0.19^{\circ}$, indicating the single phase wurtzite structure and the c-axis preferential orientation of the film. Post-growth annealing was carried out in a tube furnace in $\mathrm{Ar}$ atmosphere for a period of $30 \mathrm{~min}$.

The Hall measurement was carried out with the Accent HL5500 system at room temperature using the van der Pauw configuration. The ohmic contacts for the Hall measurement were fabricated by depositing $50 \mathrm{~nm} \mathrm{Al} \mathrm{films} \mathrm{using} \mathrm{the} \mathrm{ther-}$ mal evaporator. The room temperature CL measurement was conducted with the Oxford MonoCL system attached to the JEOL JSM-7001 F SEM.

The PAS measurement was conducted using the slow positron beam facility at the University of Hong Kong. The annihilation gamma ray energy spectra were collected using a high purity Ge detector and the corresponding nuclear electronics, which had an energy resolution of $1.3 \mathrm{keV}$ at the $514 \mathrm{keV}$ peak. The Doppler broadening of the annihilation gamma photons was monitored by way of the $S$ and $W$ parameters defined, respectively, as the ratios of the central window count and the summation of the two wings count to the total annihilation event count. The energy window for the $S$-parameter was $511 \pm 0.76 \mathrm{keV}$ and the two wing windows for the $W$-parameter were from $511 \pm 3.4 \mathrm{keV}$ to $511 \pm 6.8 \mathrm{keV}$. $S$-parameter and $W$-parameter depth profiling of the sample was obtained by varying the positron beam energy $E$ up to $20 \mathrm{keV}$. The $S-E$ and $W-E$ data were analyzed by the program VEPFIT, ${ }^{23}$ which performed the fitting by assuming a Makhovian positron implantation profile and a layered sample structure, and considering the processes of positron diffusion, positron trapping into vacancies, and positron-electron annihilation.

\section{RESULTS AND DISCUSSIONS}

The carrier concentrations of the As-doped $\mathrm{ZnO}$ samples annealed at different temperatures are tabulated in Table I. The as-grown sample fabricated at the substrate temperature

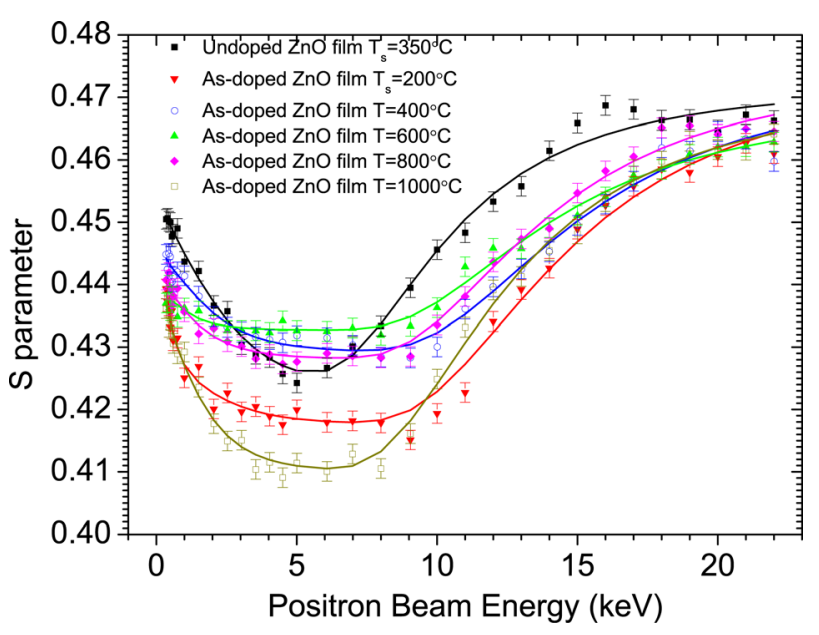

FIG. 1. (Color online) $S$-parameter as a function of the positron beam energy for the As-doped samples annealed at different temperatures. The curves are the fitted curves corresponding to the fitted parameters as shown in Table I.

of $200^{\circ} \mathrm{C}$ was $n$-type having $n=5 \times 10^{16} \mathrm{~cm}^{-3}$. After the post-growth annealing in $\mathrm{Ar}$ atmosphere at $400{ }^{\circ} \mathrm{C}$, the sample converted to $p$-type having a hole concentration of $p=2 \times 10^{17} \mathrm{~cm}^{-3}$. The hole concentration then reached a maximum of $p=6 \times 10^{17} \mathrm{~cm}^{-3}$ at the annealing temperature of $600^{\circ} \mathrm{C}$. Further increasing annealing temperature to $800^{\circ} \mathrm{C}$ would reduce the hole concentration and the sample changed back to $n$-type after the $1000^{\circ} \mathrm{C}$ annealing.

The $S$ - $E$ data of the As-doped sample annealed at different temperatures were shown in Fig. 1. The $S-E$ data (and also the $W-E$ data) were fitted by the VEPFIT program with the assumption of the two-layer model. The fitted values of the $S$-parameter, $W$-parameter, and effective positron diffusion length $L_{+}$are tabulated in Table I. The fitted curves are shown in Fig. 1, which indicate good fitting to the experimental data. The fitted $S$ and $W$-parameters for the samples annealed at different temperatures were also shown in the $S$-W plot in Fig. 2 with the fitted $L_{+}$labeled.

From Fig. 2, the $S$ parameter and the $W$ parameter of the as-grown sample were 0.417 and 0.0938 , respectively. With the annealing temperature $T_{\text {anneal }} \leq 600{ }^{\circ} \mathrm{C}$, the $S$-parameter and $W$-parameter, respectively, increased and decreased with the increasing annealing temperature. The minimum value of $S=0.433$ and the maximum value of $W=0.0870$ were observed after the sample was annealed at $600{ }^{\circ} \mathrm{C}$. The positron diffusion length $L_{+}$simultaneously decreased from the

TABLE I. Summarizing the conduction type, the carrier concentration, and the fitted results of the $S$ - $E$ data (i.e., the $S$-parameter, the $W$-parameter, and the effective positron diffusion length $L_{+}$) for the samples annealed at different temperatures.

\begin{tabular}{|c|c|c|c|c|c|c|}
\hline $\begin{array}{l}\text { Annealing } \\
\text { temperature }\end{array}$ & $\begin{array}{l}\text { As-grown } \\
\text { (substrate } \\
\text { temperature } \\
=200^{\circ} \mathrm{C} \text { ) }\end{array}$ & $400^{\circ} \mathrm{C}$ & $500^{\circ} \mathrm{C}$ & $600^{\circ} \mathrm{C}$ & $800^{\circ} \mathrm{C}$ & $1000^{\circ} \mathrm{C}$ \\
\hline $\begin{array}{l}\text { Conduction type and } \\
\text { carrier concentration }\end{array}$ & $n=5 \times 10^{16} \mathrm{~cm}^{-3}$ & $p=2 \times 10^{17} \mathrm{~cm}^{-3}$ & $p=3 \times 10^{17} \mathrm{~cm}^{-3}$ & $p=6 \times 10^{17} \mathrm{~cm}^{-3}$ & $p=4 \times 10^{16} \mathrm{~cm}^{-3}$ & $n=1 \times 10^{16} \mathrm{~cm}^{-3}$ \\
\hline Fitted results of PAS data & $\begin{array}{l}S=0.4173 \\
W=0.09384 \\
L_{+}=27 \mathrm{~nm}\end{array}$ & $\begin{array}{l}S=0.4290 \\
W=0.08830 \\
L_{+}=21 \mathrm{~nm}\end{array}$ & & $\begin{array}{l}S=0.4326 \\
W=0.08702 \\
L_{+}=8 \mathrm{~nm}\end{array}$ & $\begin{array}{l}S=0.4280 \\
W=0.09083 \\
L_{+}=16 \mathrm{~nm}\end{array}$ & $\begin{array}{l}S=0.4097 \\
W=0.1019 \\
L_{+}=17 \mathrm{~nm}\end{array}$ \\
\hline
\end{tabular}




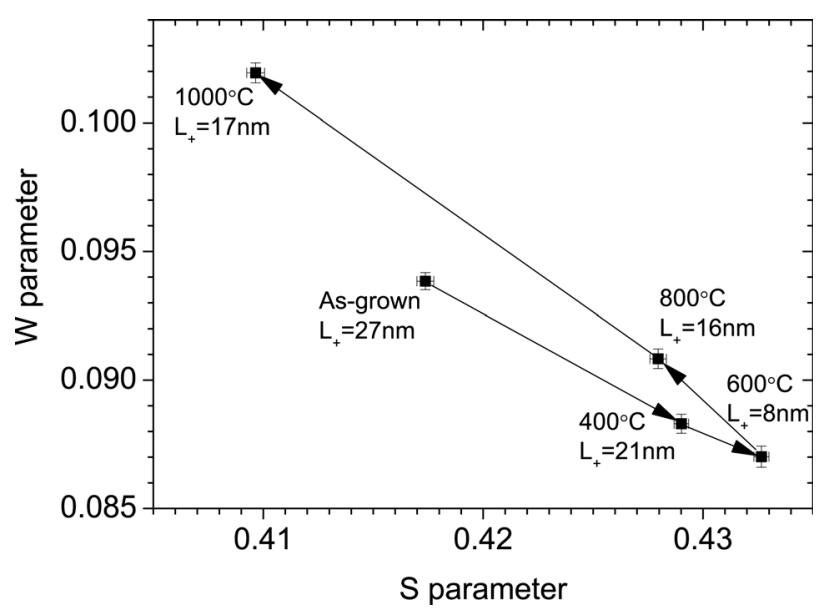

FIG. 2. $S$-parameter as a function of the $W$-parameter for samples annealed at different temperatures. The effective diffusion lengths $L_{+}$'s for each of the samples were included.

as-grown sample of $27 \mathrm{~nm}$ to the minimum of $8 \mathrm{~nm}$ of the $600{ }^{\circ} \mathrm{C}$ annealed sample. It is generally accepted that $\mathrm{Zn}$ vacancy related defect and the relevant vacancy cluster are effective positron traps in $\mathrm{ZnO}$ at room temperature. Positron annihilating from these localized states would yield a higher $S$-parameter (and lower $W$-parameter and $L_{+}$) as compared to the delocalized state. On the other hand, oxygen vacancy has a much smaller positron binding energy of $\sim 0.01 \mathrm{eV}$ $\left(\sim 0.50 \mathrm{eV}\right.$ for $\left.\mathrm{V}_{\mathrm{Zn}}\right)$ and thus thermal detrapping of positron from $V_{O}$ is significant at the room temperature. Therefore, the observed increase in $S$-parameter, and the decreases in $W$ parameter and positron diffusion length with respect to $T_{\text {anneal }}$ in the range of $T_{\text {anneal }} \leq 600{ }^{\circ} \mathrm{C}$ simply implied the increase of $\mathrm{V}_{\mathrm{Zn}}$-related defect concentration and/or the increase of the vacancy open volume. In the range of $T_{\text {anneal }}>600^{\circ} \mathrm{C}, W$ decreased, $S$ and $L_{+}$increased with increasing $T_{\text {anneal }}$. This could be explained by the decrease of the open volume of the $\mathrm{V}_{\mathrm{Zn}}$-related defect and/or the thermal removal of the $\mathrm{V}_{\mathrm{Zn}}$-related defect. The $S$-parameter and the hole concentration of the samples were also plotted together against the annealing temperature in Fig. 3. The asgrown sample was $n$-type conducting. The $S$-parameter and the hole concentration increased with $T_{\text {anneal }}$ for $T_{\text {Anneal }} \leq 600^{\circ} \mathrm{C}$, but they decreased while the annealing temperature further increased. The correlation between the $S$-parameter and the hole concentration was clearly demonstrated.

In the previous study of fabricating As-doped $\mathrm{ZnO}$ using the similar technique which involved the investigation of the effect of the substrate temperature, we have reported that the film grown at low substrate temperature $\left(200^{\circ} \mathrm{C}\right)$ was $n$-type. The conduction type of the sample changed to $p$-type $\left(p \sim 10^{17} \mathrm{~cm}^{-3}\right)$ as the substrate temperature increased to $350{ }^{\circ} \mathrm{C}$, then rose to the maximum of $\sim 10^{18} \mathrm{~cm}^{-3}$ while the substrate temperature increased to $400{ }^{\circ} \mathrm{C}$. Further increasing the substrate temperature would decrease the hole concentration. Free electron to acceptor (FA) emission $(3.282 \mathrm{eV}$ ) was identified in the low temperature $(10 \mathrm{~K})$ photoluminescence (PL) spectra of the As-doped $p$-type samples and the acceptor binding energy was thus found to be $E_{A}=155 \mathrm{meV}$.

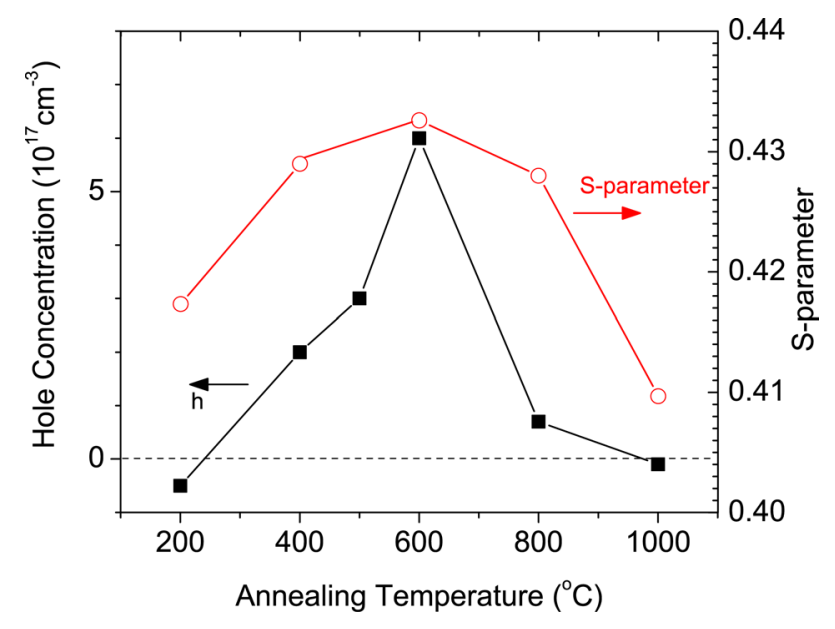

FIG. 3. (Color online) Hole concentration and S-parameter of the film as a function of the annealing temperature.

This value agreed well with the theoretical value of $\varepsilon(0 /-)=0.15 \mathrm{eV}$ of the $\mathrm{As}_{\mathrm{Zn}}\left(\mathrm{V}_{\mathrm{Zn}}\right)_{2}$ acceptor, ${ }^{24}$ and thus the shallow acceptor was attributed to this defect. XPS was also employed to study the occupying site of the As-atom in the $\mathrm{ZnO}$ lattice by monitoring the As (3d) binding energy. For the As-doped $\mathrm{ZnO}$ samples grown by the RF magnetron sputtering, a single dominant peak of $\sim 45 \mathrm{eV}$ was found. This peak corresponded to the As-O bond rather than the As$\mathrm{Zn}$ bond $(\sim 41 \mathrm{eV})$, thus indicating that the majority of the As-atom occupied the $\mathrm{Zn}$-site in the $\mathrm{ZnO}$ lattice. This implied that the introduced As dopant formed a defect containing the $\mathrm{As}_{\mathrm{Zn}}$ microstructure, which also agreed with the proposed $\mathrm{As}_{\mathrm{Zn}}\left(\mathrm{V}_{\mathrm{Zn}}\right)_{2}$ shallow acceptor model. Moreover, the S-parameter of the As-doped $\mathrm{ZnO}$ film also rose with the hole concentration as the substrate temperature was increased. This was thought to be related to the open volume increase of the Zn-vacancy. According to the first principle calculation of the $\mathrm{As}_{\mathrm{Zn}}\left(\mathrm{V}_{\mathrm{Zn}}\right)_{2}$ structure, the O-atom sitting adjacent to the As atom and the Zn-vacancy would be relaxed toward the As-atom. This atomic relaxation would lead to the increase of the Zn-vacancy open volume.

In Fig. 3, the $n$-type film was converted to $p$-type after the $400^{\circ} \mathrm{C}$ annealing and the hole concentration increased further while the annealing temperature reached $600^{\circ} \mathrm{C}$. These observations were associated with the formation of the $\mathrm{As}_{\mathrm{Zn}}\left(\mathrm{V}_{\mathrm{Zn}}\right)_{2}$ shallow acceptor. The corresponding increase of $S$-parameter was due to the increase of $\mathrm{V}_{\mathrm{Zn}}$ open volume originated from the atom relaxation of the $\mathrm{As}_{\mathrm{Zn}}\left(\mathrm{V}_{\mathrm{Zn}}\right)_{2}$ defect.

However, as shown in Fig. 3, further increasing the annealing temperature would decrease the hole concentration and the $S$ parameter. The decrease of the hole concentration could be due to the formation of compensating defects and/ or the thermal dissociation of the $\mathrm{As}_{\mathrm{Zn}}\left(\mathrm{V}_{\mathrm{Zn}}\right)_{2}$ shallow acceptor at high annealing temperature. The corresponding decrease of the $S$-parameter supported the idea of the dissociation of $\mathrm{As}_{\mathrm{Zn}}\left(\mathrm{V}_{\mathrm{Zn}}\right)_{2}$. It is because the resultant isolated $\mathrm{V}_{\mathrm{Zn}}$ has a smaller volume than the $\mathrm{V}_{\mathrm{Zn}}$ attached to the $\mathrm{As}_{\mathrm{Zn}}\left(\mathrm{V}_{\mathrm{Zn}}\right)_{2}$ and thus would lead to the decrease of the $S$-parameter. We have also carried out XPS measurement on the $1000^{\circ} \mathrm{C}$ annealed As-doped sample and the As (3d) XPS spectrum still contained the $45 \mathrm{eV}$ single peak, thus implying that the 
majority of the As-atom remained as the $\mathrm{As}_{\mathrm{Zn}}$ structure. It is thus plausible to suggest that the $\mathrm{As}_{\mathrm{Zn}}\left(\mathrm{V}_{\mathrm{Zn}}\right)_{2}$ acceptor complex decomposes into isolated Zn-vacancy and $\mathrm{As}_{\mathrm{Zn}}$ substitute defect.

It is also worth estimating the annealing temperature from the theoretical binding energy of $\mathrm{As}_{\mathrm{Zn}}\left(\mathrm{V}_{\mathrm{Zn}}\right)_{2}$ and comparing it with the experimental findings. The frequency for a nearby atom jumping to a vacancy is given by $\Gamma=\Gamma_{0} \exp \left(-E_{b} / k T\right)$, where $E_{b}$ is the corresponding energy barrier, and $\Gamma_{0}$ is the vibration frequency from the initial configuration to the configuration corresponding to the saddle point. Taking $\Gamma=1 \mathrm{~s}^{-1}, \Gamma_{0}=10^{13} \mathrm{~s}^{-1}$ (which is a typical phonon frequency) (Ref. 25, and references therein), and $E_{b}=2.84 \mathrm{eV}$ for the $\mathrm{As}_{\mathrm{Zn}}\left(\mathrm{V}_{\mathrm{Zn}}\right),{ }^{24}$ the annealing temperature was found to be $\sim 800^{\circ} \mathrm{C}$, which agreed with the drop-off temperature for the hole concentration and $S$-parameter (Fig. 3).

The SIMS depth profile of the Si, Zn, and O for the asgrown and the $800^{\circ} \mathrm{C}$ annealed samples are shown in Figs. 4(a) and 4(b), respectively. As shown in Fig. 4(a), Si$\mathrm{Zn}$ inter-mixing was found at the as-grown $\mathrm{ZnO} / \mathrm{SiO}_{2}$ boundary with a width of $\sim 30 \mathrm{~nm}$. After the $800^{\circ} \mathrm{C}$ annealing, $\mathrm{Zn}$ diffused into the $\mathrm{SiO}_{2}$ extending to a depth of about $60 \mathrm{~nm}$ the $\mathrm{Si}$ atom diffused into the whole $\mathrm{ZnO}$ film. This would inevitably introduce defects in the interface as well as in the whole $\mathrm{ZnO}$ film.

CL measurements were carried out on the samples annealed at different temperatures using two different electron beam energies, namely $E_{b}=5 \mathrm{keV}$ and $10 \mathrm{keV}$. According to the empirical equation of Everhart and Hoff, ${ }^{26}$

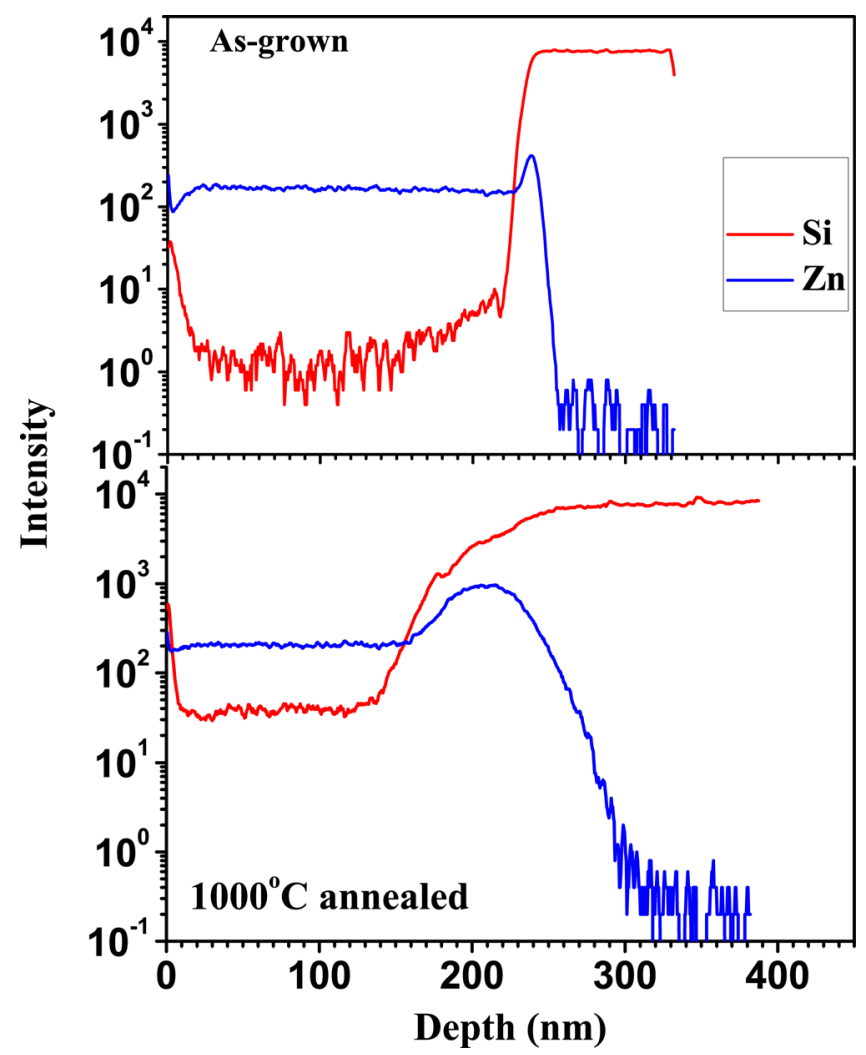

FIG. 4. (Color online) SIMS depths of $\mathrm{Si}$ and $\mathrm{Zn}$ for the as-grown and the $1000^{\circ} \mathrm{C}$ annealed As-doped $\mathrm{ZnO}$ samples. the electron penetration range $R_{e}$ (in $\mu \mathrm{m}$ ) is given by $R_{e}=(0.0398 / \rho) E_{b}^{1.75}$, where $\rho$ is in $\mathrm{g} \mathrm{cm}^{-3}$ and $E_{b}$ is in $\mathrm{keV}$. The electron energy of $5 \mathrm{keV}$ and $10 \mathrm{keV}$ adopted in the present $\mathrm{CL}$ study of $\mathrm{ZnO}$ thus corresponded to the penetration depths of $120 \mathrm{~nm}$ and $390 \mathrm{~nm}$, respectively. As the $\mathrm{ZnO}$ film thickness was $\sim 300 \mathrm{~nm}$, the CL spectrum obtained from $E_{b}=5 \mathrm{keV}$ thus involved the majority of the luminescence originated from the front half of the sample, while that from $E_{b}=10 \mathrm{keV}$ involved luminescence originated from the whole $\mathrm{ZnO}$ film, and the $\mathrm{ZnO} / \mathrm{SiO}_{2}$ interface.

Figures 5(a) and 5(b) are the CL spectra of the As-doped $\mathrm{ZnO}$ samples obtained from the electron beam energy $E_{b}=5 \mathrm{keV}$ and $10 \mathrm{keV}$, respectively. For the $E_{b}=5 \mathrm{keV}$ spectrum, three peaks at $1.6 \mathrm{eV}, 2.5 \mathrm{eV}$, and $3.2 \mathrm{eV}$ were identified. These three peaks were also found in the $E_{b}=10 \mathrm{keV}$ spectrum of the samples. In addition, two other peaks $(2.8 \mathrm{eV}$ and $3.0 \mathrm{eV})$ were only identified in the $E_{b}=10 \mathrm{keV}$ spectra.

The near-band-edge emission $3.2 \mathrm{eV}$ was observed in all of CL spectra. Annealing had the effect of increasing its intensity, which could be due to the removal of the non-
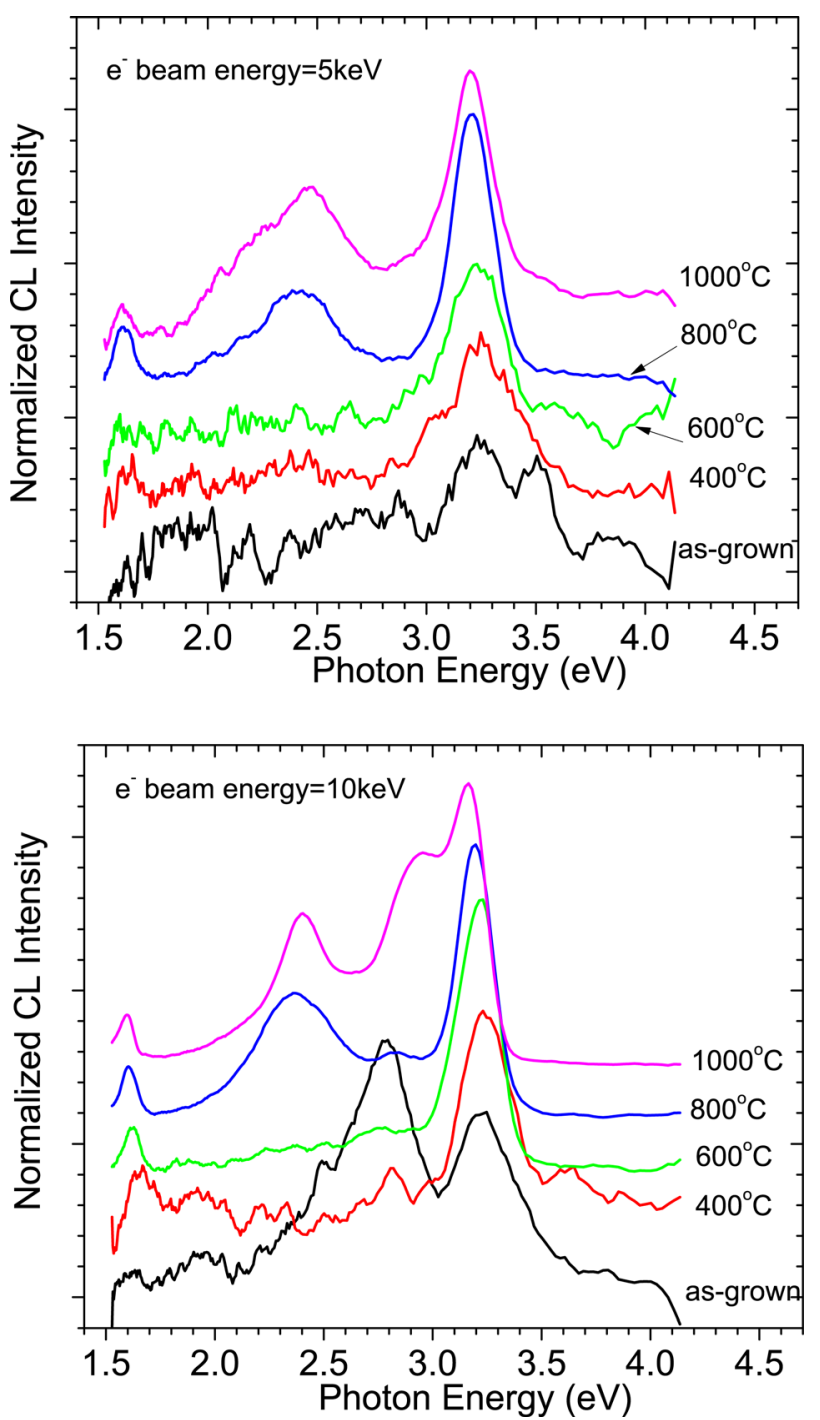

FIG. 5. (Color online) CL spectra of the samples annealed at different temperatures with the electron beam energy equal to (a) $5 \mathrm{keV}$ and (b) $10 \mathrm{keV}$. 
radiative defects and the improvement of the crystalline quality.

As shown in the previous paragraph, our SIMS results showed that there were $\mathrm{Zn}-\mathrm{Si}$ inter-diffusion at the $\mathrm{ZnO}$ / $\mathrm{SiO}_{2}$ interface of the as-grown samples and the interdiffusion would be significantly enhanced by thermal annealing. Studying the near-interfacial defects of oxide/ $\mathrm{ZnO}$ interface, Wang et al. ${ }^{27}$ also showed that deep level defects were easily formed at the near-interfacial region, and it had the effect of enhancing the defect emission. In the present study, the $2.8 \mathrm{eV}$ and the $3.0 \mathrm{eV}$ peaks were only found in the $E_{b}=10 \mathrm{keV}$ spectra, and were thus thought to be associated with defects located closer to the $\mathrm{ZnO} / \mathrm{SiO}_{2}$ interface. The $2.8 \mathrm{eV}$ peak was observed in the as-grown sample, but vanished after the $400{ }^{\circ} \mathrm{C}$ annealing. The $3.0 \mathrm{eV}$ peak was induced after the $1000^{\circ} \mathrm{C}$ annealing. $\mathrm{CL}$ measurement was also conducted on the as-grown and the $1000^{\circ} \mathrm{C}$ annealed $\mathrm{SiO}_{2}$ substrate and no similar luminescence was observed, confirming that the two observed peaks were not originated from the substrate. Broad defect emission with similar peak $(2.85 \mathrm{eV})$ has previously been reported in metalorganic chemical vapor deposition (MOCVD) grown O-rich $\mathrm{ZnO}^{28}$ The author ascribed this to the $\mathrm{Zn}_{\mathrm{i}}$ to $\mathrm{V}_{\mathrm{Zn}}$ transition, ${ }^{28}$ though concrete evidence has not been obtained.

The $1.6 \mathrm{eV}$ peak was observed in both the $E_{b}=5 \mathrm{keV}$ and $10 \mathrm{keV} \mathrm{CL}$ spectra. Irrespective of $E_{b}$, annealing at $T_{\text {anneal }} \leq 800^{\circ} \mathrm{C}$ had an effect of enhancing the peak intensity, which then saturated at $1000^{\circ} \mathrm{C}$ annealing. Ong et al. ${ }^{29}$ has reported a close-by CL peak of $1.69 \mathrm{eV}$, which was attributed to defect or the second order band edge emissions.

The broad peak centered at $\sim 2.4 \mathrm{eV}$ observed in both the $E_{b}=5 \mathrm{keV}$ and $10 \mathrm{keV}$ spectra was commonly termed the green luminescence GL. The origin of the GL is still controversial. Structureless GL emission has been associated with $\mathrm{V}_{\mathrm{O}}$ (Refs. 30-32) and $\mathrm{V}_{\mathrm{Zn}} \cdot{ }^{25,33}$ In the present study, the annealing behavior of the GL was independent of the electron beam energy $E_{b}$. The GL was not found in the as-grown sample. Irrespective of the electron beam energy (as shown in Fig. 5), annealing the sample at $800^{\circ} \mathrm{C}$ would induce significant GL defect emission and it persisted after the $1000^{\circ} \mathrm{C}$ annealing. These deep level defects associated with the GL would act as the compensating center against the $p$-type doping of the $\mathrm{ZnO}$ film, and would thus lead to the vanish of the $p$-type conduction property observed in the range of $T_{\text {anneal }}=800-1000^{\circ} \mathrm{C}$.

\section{CONCLUSION}

Using RF magnetron sputtering, As-doped $\mathrm{ZnO}$ films were grown on $\mathrm{SiO}_{2}$ at a substrate temperature of $200^{\circ} \mathrm{C}$. The resultant film was initially $n$-type. It converted to $p$-type conductive after the $400^{\circ} \mathrm{C}$ annealing. The formation of the $p$-type conductivity was attributed to the formation of the $\mathrm{As}_{\mathrm{Zn}}\left(\mathrm{V}_{\mathrm{Zn}}\right)_{2}$ shallow acceptor. However, further increasing the annealing temperature decreased the hole concentration. This was explained in terms of the formation of the compensating defect associated with the GL and the dissociation of the $\mathrm{As}_{\mathrm{Zn}}\left(\mathrm{V}_{\mathrm{Zn}}\right)_{2}$ shallow acceptor.

\section{ACKNOWLEDGMENTS}

This work was financially supported by the Research Grant Council HKSAR through the General Research Fund (GRF) (HKU7031/08P and HKU7021/10P) and The University of Hong Kong's University Development Fund (UDF) and Small Project Grant.

${ }^{1}$ Zinc Oxide Bulk, Thin Films and Nanostructures Processing, Properties and Applications, edited by C. Jagadish and S. J. Pearton (Elsevier, New York, 2006).

${ }^{2}$ Ü. Özgür, Ya. I. Alivov, C. Liu, A. Teke, M. A. Reshchikov, S. Doğan, V. Avrutin, S.-J. Cho and H. Morkoç, J. Appl. Phys. 98, 041301 (2005).

${ }^{3}$ D. C. Look, Phys. Status Solidi B 241, 624 (2004).

${ }^{4}$ V. Avrutin, D. J. Silversmith, and H. Morkoç, Proc. IEEE 98, 1269 (2010).

${ }^{5}$ Positron Beams and Their Applications, edited by P. Coleman (World Scientific, Singapore, 2000).

${ }^{6} \mathrm{R}$. Krause-Rehberg and H. S. Leipner, Positron Annihilation in SemiconductorsDefect Studies (Springer, Berlin, 1999).

${ }^{7}$ S. Brunner, W. Puff, A. G. Balogh, P. Mascher, W. Triftshauser, G. Kogel, and P. Sperr, Mater. Sci. Forum 363-3, 141 (2001).

${ }^{8}$ F. Tuomisto, V. Ranki, K. Saarinen, and D. C. Look, Phys. Rev. Lett. 91, 205502 (2003).

${ }^{9}$ Z. Q. Chen, S. J. Wang, M. Maekawa, A. Kawasuso, H. Naramoto, X. L. Yuan, and T. Sekiguchi, Phys. Rev. B 75, 245206 (2007).

${ }^{10}$ G. Brauer, W. Anwand, D. Grambole, J. Grenzer, W. Skorupa, J. Čižek, J. Kuriplach, I. Procházka, C. C. Ling, C. K. So, D. Schulz, and D. Klimm, Phys. Rev. B 79, 115212 (2009).

${ }^{11}$ W. Anwand, G. Brauer, R. I. Grynszpan, T. E. Cowan, D. Schulz, D. Klimm, J. Čižek, J. Kuriplach, I. Procházka, C. C. Ling, A. B. Djurišić, V. Klemm, G. Schreiber, and D. Rafaja, J. Appl. Phys. 109, 063516 (2011).

${ }^{12}$ A. Uedono, T. Koida, A. Tsukazaki, M. Kawasaki, Z. Q. Chen, S. Chichibu, and H. Koinuma, J. Appl. Phys. 93, 2481 (2003).

${ }^{13}$ T. Koida, S. F. Chichibu, A. Uedono, A. Tsukazaki, M. Kawasaki, T. Sota, Y. Segawa, and H. Koinuma, Appl. Phys. Lett. 82, 532 (2003).

${ }^{14}$ J. C. Fan, C. Y. Zhu, S. Fung, Y. C. Zhong, K. S. Wong, Z. Xie, G. Brauer, W. Anwand, W. Skourpa, C. K. To, B. Yang, C. D. Beling, and C. C. Ling, J. Appl. Phys. 106, 073709 (2009).

${ }^{15}$ K. H. Tam, C. K. Cheung, Y. H. Leung, A. B. Djurišić, C. C. Ling, C. D. Beling, S. Fung, W. M. Kowk, W. K. Chan, D. L. Philips, L. Ding, and W. K. Ge, J. Phys. Chem. B 110, 20865 (2006).

${ }^{16}$ Y. F. Hsu, Y. Y. Xi, K. H. Tam, A. B. Djurišić, J. M. Luo, C. C. Ling, C. K. Cheung, A. M. C. Ng, W. K. Chan, X. Deng, C. D. Beling, S. Fung, K. W. Cheah, P. W. K. Fong, and C. C. Surya, Adv. Funct. Mater. 18, 1020 (2008).

${ }^{17}$ Q. L. Gu, C. C. Ling, X. D. Chen, C. K. Cheung, A. M. C. Ng, C. D. Beling, S. Fung, A. B. Djurišić, L. W. Lu, G. Brauer, and H. C. Ong, Appl. Phys. Lett. 90, 122101 (2007).

${ }^{18}$ Q. L. Gu, C. K. Cheung, C. C. Ling, A. M. C. Ng, A. B. Djurišić, L. W. Lu, X. D. Chen, S. Fung, C. D. Beling, and H. C. Ong, J. Appl. Phys. 103, 093706 (2008).

${ }^{19}$ G. Brauer, W. Anwand, W. Skorupa, J. Kuriplach, O. Meliknova, C. Moisson, H. Von Wenckstern, H. Schmidt, M. Lorenz, and M. Grundmann, Phys. Rev. B 74, 045208 (2006)

${ }^{20}$ Z. Q. Chen, A. Kawasuso, Y. Xu, H. Naramoto, X. L. Yuan, T. Sekiguchi, R. Suzuki, and T. Ohdaira, J. Appl. Phys. 97, 013528 (2005).

${ }^{21}$ M. Khalid, M. Zlese, A. Setzer, P. Esquinazi, M. Lorenz, H. Hochmuth, M. Grundmann, D. Spemann, T. Butz, G. Brauer, W. Anwand, G. Fisher, W. A. Adeagbo, W. Hergert, and A. Emst, Phys. Rev. B 80, 035331 (2009).

${ }^{22}$ J. C. Fan, G. W. Ding, S. Fung, Z. Xie, Y. C. Zhong, K. S. Wong, G. Brauer, W. Anwand, D. Grambole, and C. C. Ling, Semicond. Sci. Technol. 25, 085009 (2010).

${ }^{23}$ A. van Veen, H. Schut, J. de Vries, R. A. Hakvoort, and M. R. Ijpma, AIP Conf. Proc. 218, 171 (1990).

${ }^{24}$ S. Limpijumnong, S. B. Zhang, S.-H. Wei, and C. H. Park, Phys. Rev. Lett. 89, 222113 (2006).

${ }^{25}$ Anderson Janotti and C. G. Van de Walle, Phys. Rev. B 76, 165202 (2007).

${ }^{26}$ T. E. Everhart and P. H. Hoff, J. Appl. Phys. 42, 5837 (1971).

${ }^{27}$ R. S. Wang, Q. L. Gu, C. C. Ling, and H. C. Ong, Appl. Phys. Lett. 92, 042106 (2008). 
${ }^{28}$ C. H. Ahn, Y. Y. Kim, D. C. Kim, S. K. Mohanta, and H. K. Cho, J. Appl. Phys. 105, 013502 (2009).

${ }^{29}$ H. C. Ong, A. S. K. Li, and G. T. Du, Appl. Phys. Lett. 78, 2667 (2001).

${ }^{30}$ K. Vanheusden, C. H. Seager, W. L. Warren, D. R. Tallant, and J. A. Voigt, Appl. Phys. Lett. 68, 403 (1996).
${ }^{31}$ S. A. Studenikin, N. Golego, and M. Cocivera, J. Appl. Phys. 84, 2287 (1998).

${ }^{32}$ F. H. Leiter, H. R. Alves, A. Hofstaetter, D. M. Hoffmann, and B. K. Meyer, Phys. Status. Solidi B 226, R4 (2001).

${ }^{33}$ D. C. Reynolds, D. C. Look, B. Jogai, and H. Morkoç, Solid State Commun. 101, 643 (1997). 